\title{
Anorexia Nervosa: een integratief behandelmodel
}

Samenvatting

Anorexia Nervosa: een integratief behandelmodel

Anorexia Nervosa (AN) is een ziekte met een sombere prognose en een grote impact op het leven van een individu en diens omgeving. Ondanks de grote diversiteit aan behandelvormen blijft de behandeling van AN gekenmerkt door een beperkte empirische basis en een hoge drop-out. Als reactie hierop is er de laatste jaren een toename van multidisciplinaire behandelmodellen, waarin verschillende methodieken met elkaar gecombineerd worden. Omwille van de beperkte wetenschappelijke evidentie is het noodzakelijk om dergelijke integratieve modellen uitvoerig te beschrijven. Zo kan immers een uitwisseling van kennis en expertise op gang komen tussen verschillende behandelpraktijken. Daarom wordt in dit artikel de werking van Empathie, een therapeutisch centrum voor de behandeling van AN in Gent (België), beschreven. In het therapeutisch model van Empathie wordt een systeemtherapeutische aanpak gecombineerd met aspecten uit het oplossingsgericht denken.

\section{Introductie}

Anorexia Nervosa (AN) is een ziekte met een enorme impact op alle levensdomeinen van een individu en diens context (Jones, Evans e.a., 2008). AN-patiënten leven als het ware onder de dictatuur van de 'innerlijke criticus', een sterke innerlijke normerende stem die steeds dezelfde afkeurende oordelen herhaalt. Stinckens (2001) hanteert deze metafoor om te verwijzen naar 'een geïntegreerd systeem van kritische en negatieve gedachten en attitudes ten aanzien van het zelf, dat werd opgedrongen van buitenaf'. De innerlijke criticus manifesteert zich op verschillende manieren, waardoor emotioneel welzijn en sociale relaties te lijden hebben onder de vele eisen die hij stelt t.a.v. de patiënt. Bovendien kent AN een sombere prognose. Minder dan de helft van de patiënten herstelt volledig van de ziekte. 20 procent ontwikkelt een chronische eetstoornis en 5 procent van de AN-patiënten overlijdt aan de gevolgen van de ziekte of door zelfdoding (; Steinhausen, 2002; Steinhausen, 2008).

Er is een brede kennisbasis voorhanden wat betreft de prognose, kenmerken en medische aspecten van AN, maar over de behandeling blijft de kennis veel schaarser (Lock \& Le Grange, 2001). Nochtans bestaat er een grote diversiteit aan behandelvormen, gaande van 
intensieve residentiële begeleiding over ambulante zorg tot therapie via internet of telefoon. Deze behandelvormen baseren zich op (een combinatie van) diverse therapeutische benaderingen: cognitive remediation therapy (CRT), mindfulness, gedragstherapie, acceptance and commitment therapy (ACT), spiegeltherapie, motivationeel interviewen, cognitief-affectieve therapie, gezinstherapie, etc. (Alberts e.a., 2012;; Goodier et al., 2014; Pretorius \& Tchanturia, 2007; Smit e.a., 2009; Tenwolde, 2001). Voor weinig behandelingen is er echter een sterke empirische basis ontwikkeld (Fairburn, 2005; Guarda, 2008; NICE, 2004;). Daarnaast worden de behandelingen waarvoor wel een zekere evidentie bestaat, zoals family-based therapy, vaak gekenmerkt door een hoge drop-out (Berg \& Wonderlich, 2013; Lock \& Le Grange, 2001).

Omwille van het gebrek aan wetenschappelijke evidentie gaan steeds meer stemmen op voor een integratieve multidisciplinaire behandeling van AN (Hatch e.a., 2010; NICE, 2004). Bovendien heeft AN een complexe etiologie waarin zowel genetische, biologische, psychologische als socioculturele factoren een rol spelen. Daarom wordt ook vanuit de hoek van het neurobiologisch onderzoek gepleit voor een multidisciplinaire aanpak (Connan e.a., 2003). Onder invloed van die bevindingen kwam er de laatste jaren een snelle toename van nieuwe behandelmodellen voor eetstoornissen, waarin verschillende theoretische kaders en methodieken gecombineerd worden (Berg \& Wonderlich, 2013). Een dergelijk therapiemodel is het MANTRA-model (Maudsley Model of Anorexia Nervosa Treatment for Adults), dat ontwikkeld werd aan het King's College Institute of Psychiatry in Londen. MANTRA is gebaseerd op een cognitief-interpersoonlijk model waarin vier factoren naar voor geschoven worden die AN in stand houden: een rigide cognitieve denkstijl, een vermijdende emotionele en relationele stijl, pro-anorexia overtuigingen en sterk emotionele reacties van personen uit de context van de patiënt die onbedoeld de AN mee in stand houden. Het vormt een breuk met de klassieke cognitieve gedragstherapie, omdat gewicht niet gezien wordt als de kernpsychopathologie maar als een symptoom van een onderliggende problematiek. Het programma is modulair opgebouwd en krijgt vorm via 20 tot 40 individuele ambulante sessies, waarin de nadruk ligt op motivatie, cognitieve denkstijlen, emoties, identiteit, het herstellen van een gezond voedingspatroon en het aanleren van vaardigheden aan de ouders. Bijzonder aan MANTRA is het feit dat er gewerkt wordt aan de hand van een handboek dat de leidraad vormt doorheen de behandeling (Schmidt e.a., 2014). Vergelijkende onderzoeken tonen preliminaire evidentie voor bepaalde componenten van het MANTRA-model, zoals het 
gebruik van een dagboek en de therapeutische stijl (Grover e.a.., 2011; Hoyle e.a., 2013; Wade e.a., 2011).

Omwille van de beperkte empirische basis voor de behandelingen van AN is het noodzakelijk om nieuwe behandelmodellen, zoals het MANTRA-model, te identificeren en te beschrijven (Berg \& Wonderlich, 2013). Binnen dergelijke modellen worden vaak verschillende methodieken en aanpakken met elkaar gecombineerd, met het oog op een zo goed mogelijk herstel voor de patiënten. Door de werking van deze multi-methodische behandelpraktijken zo transparant mogelijk te maken, kan de kennisbasis rond de behandeling van AN verder uitgebreid worden. Vanuit dat oogpunt wordt in dit artikel ingezoomd op Empathie, een ambulant therapeutisch centrum voor de behandeling van AN in Gent (België) dat werd opgestart in 2004. Gebaseerd op verschillende theoretische kaders en vanuit een holistische en multidisciplinaire aanpak neemt Empathie de totale impact van een eetstoornis op de kwaliteit van leven van de patiënt in acht. Net zoals bij MANTRA worden gewicht en lichaamsvorm niet beschouwd als de kernpsychopathologie van de stoornis (Schmidt, Wade \& Treasure, 2014). In het programma worden elementen uit de oplossingsgerichte en cliëntgerichte therapie gecombineerd met een systemische en familiegerichte benadering. In dit artikel worden de visie, doelstellingen, doelgroep, aanpak en context van het Empathie-programma gespecificeerd.

\section{Methodologie}

Om een zo volledig mogelijk beeld te krijgen van de aanpak van Empathie werd door de eerste auteur informatie verzameld langs diverse kanalen. Zo vonden drie interviews met de coördinatoren plaats, waarin de inhoud en theoretische achtergrond van de behandeling uitgebreid besproken werden. Als aanvulling hierop werden de aanwezige werkingsdocumenten van Empathie (intake-formulier, website) bestudeerd. Ook werden de andere betrokken therapeuten (mindfulness-coach, dramatherapeute) gecontacteerd om hun aandeel in de therapie toe te lichten. Daarnaast voerde de onderzoeker (eerste auteur) gedurende één volledige dag een participerende observatie uit tijdens de werking van het dagcentrum. Ook werd een literatuurstudie uitgevoerd naar AN en de theoretische achtergrond van de behandeling van Empathie. In een tweede fase werden de bevindingen van de onderzoeker getoetst aan de praktijkervaring van de therapeuten door opnieuw met hen in gesprek te gaan. 


\section{Therapeutisch centrum Empathie}

\subsection{Doelgroep}

Empathie richt zich zowel tot kinderen als volwassenen met AN, zoals beschreven in de DSM-IV. Hierbinnen kunnen twee types van AN onderscheiden worden, namelijk het restrictieve type en het purgerende type. Bij het restrictieve type is de patiënt niet geregeld bezig met vreetbuien en purgerende maatregelen, bij het purgerende type wel. Empathie biedt therapeutische hulp aan personen die gekenmerkt worden door beide types maar hanteert wel enkele contra-indicatiecriteria, namelijk. co-morbiditeit met psychiatrische stoornis (bv. persoonlijkheidsstoornis), gebrek aan bereidwilligheid van de ouders om deel te nemen aan de therapie, een persoonlijkheid van de patiënt die botst met de dynamiek in de groep van het dagcentrum en een leeftijd jonger dan 12 jaar. In deze situaties worden patiënten doorverwezen naar beter passende behandelvormen. De intake wordt uitgevoerd door de systeemtherapeut van Empathie en gebeurt op basis van een vragenlijst en een gesprek met de patiënt en diens ouders.

\subsection{Team}

De vaste kern van het Empathie-team bestaat uit twee behandelende artsen-therapeuten. Verder wordt in Empathie samengewerkt met een nutritionist, dramatherapeut en mindfulness-coach die instaan voor de aanvullende behandelingen, voornamelijk tijdens de werking van het dagcentrum. Ook wordt er voor elke patiënt gecommuniceerd met een externe behandelende arts over de medische aspecten van de behandeling. Zo kan in onderling overleg beslist worden of het al dan niet veilig is voor de patiënt om ambulant begeleid te worden. Wanneer een patiënt nog naar school gaat, wordt ook samengewerkt met de klas en de betrokken leerkrachten. Zo wonen de therapeuten minstens één klassenraad bij en gaan ze op bezoek in de klas om aan klasgenoten uit te leggen wat het betekent om AN te hebben.

Omwille van enkele praktische en pragmatische problemen stemt de ideaaltypische vorm van Empathie niet altijd overeen met de dagelijkse praktijk. Daardoor is het niet altijd mogelijk om de aanvullende therapieën (mindfulness, drama, etc.) op elk moment aan te bieden.

\subsection{Theoretische oriëntatie}

In Empathie worden elementen van verschillende theoretische invalshoeken met elkaar gecombineerd. De aanpak is oplossingsgericht, in die zin dat er zoveel mogelijk gefocust wordt op de krachten van de patiënt en positieve aspecten van diens dagelijks leven. Zo wordt vaak gepeild naar uitzonderingen op het problematisch gedrag. Het Brugse Model, een model 
voor korte oplossingsgerichte therapie dat ontwikkeld werd aan het Korzybski-Instituut, vormt een belangrijke inspiratiebron voor de Empathie-aanpak. Binnen dit model wordt de patiënt via oplossingsgericht taalgebruik uitgenodigd om samen te zoeken naar de kortst mogelijke weg om de eigen krachten terug te vinden en te benutten (Korzybski-Instituut, 2014). In het Brugse Model worden therapeutische doelen bepaald die klein, haalbaar en waardevol geacht worden door de patiënt zelf. De therapeut bepaalt niet zelf de richting van de behandeling, maar schept een alternatieve context waarbinnen de patiënt nieuwe keuzes kan maken. Binnen de Empathie-aanpak, waar de therapeut de rol van coach inneemt, wordt hier veel aandacht aan besteed. Ook het MANTRA-model, dat hierboven kort toegelicht werd, vormt een belangrijke inspiratiebron voor de werking van Empathie.

Daarnaast is in Empathie een duidelijk systemische insteek aanwezig. Een eetstoornis is erg ingrijpend, zowel voor de patiënt als diens familie. Het trauma dat de patiënt ervaart, wordt immers ervaren door het hele gezin (Figley \& Kiser, 2013). Vanuit systemisch oogpunt wordt een eetstoornis gezien als een symptoom van een dieperliggende problematiek in het familiesysteem. Om hieraan tegemoet te komen bestaat een belangrijk deel van de therapie in Empathie uit ouderbegeleiding.

\subsection{Inhoud van de behandeling}

Het Empathie-programma bestaat uit drie luiken: individuele consultaties, ouderbegeleiding en een therapeutisch groepsprogramma in het dagcentrum. In veel gevallen is er een overlap tussen de consultaties en de ouderbegeleiding, in die zin dat bij de consultaties vaak zowel de ouders als de patiënt aanwezig zijn. De frequentie en intensiteit van dergelijke consultaties is afhankelijk van de leeftijd van de patiënt en diens vermogen om eigen emoties zelf te kunnen benoemen. Toch worden de afzonderlijke ouderconsultaties ook onmisbaar geacht door de therapeuten, omdat ouders hun angsten en noden moeten kunnen verwoorden zonder de aanwezigheid van hun kind. De combinatie van de drie luiken in een multimethodische aanpak maakt mogelijk dat elke patiënt een geïndividualiseerd behandeltraject kan doorlopen, aangepast aan de eigen zorgbehoefte.

\subsubsection{Individuele consultaties}

De consultaties vormen het fundament van de behandeling. Typerend voor de aanpak is het feit dat er op geen enkel moment in het therapieverloop een schuldvraag naar voor wordt geschoven. De focus ligt uitdrukkelijk op het hier en nu, niet in het verleden of een onzekere toekomst. Bij de start van de therapie wordt steeds dezelfde vraag gesteld: 
"Wat heb je vandaag nodig, opdat je...

... je minder rot zou voelen?

... minder aan eten zou denken?

... iets meer zou durven eten?"

Aan de hand van deze vraag wordt nagegaan of de patiënt al dan niet een werkbare hulpvraag heeft. Therapie is niet mogelijk zonder een mandaat van de patiënt om samen aan de slag te gaan. Een dergelijk initieel mandaat moet worden versterkt tot een circulair mandaat dat pas kan ontstaan wanneer de patiënt zich durft openstellen voor motivatie tot verandering. Wanneer er een dergelijk circulair mandaat aanwezig is, wordt de patiënt beschouwd als expert en wordt er een beroep gedaan op diens sterktes. In dat opzicht is de Empathie-aanpak Rogeriaans, omdat de therapeuten uitgaan van de assumptie dat de patiënt over het vermogen tot zelfdeterminatie beschikt en de innerlijke kracht in zich draagt om de eetstoornis te overwinnen (Witty, 2007). Vanuit die aanname gaat de therapeut samen met de patiënt aan de slag om een context te creëren waarbinnen de patiënt zelf oplossingen kan genereren (Korzybski-Instituut, 2014). Hierbij maakt de therapeut soms gebruik van het principe van 'herkaderen' van Bateson (1980), waarbij halsstarrige gedachten van de patiënt omgebogen worden door ze te belichten vanuit een ander perspectief. Zo hebben AN-patiënten soms het idee dat hun omgeving zich 'bemoeit' met hun leven. Een dergelijk idee wordt dan geherformuleerd naar 'bezorgdheid' vanwege de omgeving. In Empathie ligt de focus op 'het kleinst mogelijke stapje vooruit', zodat de patiënt het stapje vooruit zelf ook als realistisch inschat en zich steeds veilig blijft voelen. In Empathie neemt de therapeut de positie in van coach.

\subsubsection{Ouderbegeleiding}

Aanvullend op de consultaties is ook ouderbegeleiding een onmisbare schakel in het therapeutisch programma van Empathie. Patiënten met Anorexia Nervosa kampen vaak met een gespleten loyaliteit ten aanzien van ouders en familie.. Dit loyaliteitsconflict kan pathologische uitwerkingen hebben, omdat het in staat is intergenerationeel vertrouwen binnen een gezin te vernietigen (Dillen, 2004). AN kan gezien worden als het symptoom van een dieperliggende gezinsproblematiek, maar schuldvragen zijn in de Empathie-aanpak niet aan de orde. De eetstoornis vormt juist een aangrijpingspunt om bepaalde gewoontes in het gezin te veranderen. Tijdens de contextbegeleiding krijgen de ouders praktische handvatten aangereikt om de taal van het anorectisch systeem bij hun kind te leren herkennen. Door de ouders een bepaald taalgebruik aan te leren, kunnen ze de 'ongezonde denker' de mond 
snoeren en de 'gezonde denker' in hun kind aan het woord laten. Een ander belangrijk aspect van de ouderbegeleiding is het feit dat de ouders uitgenodigd worden tot introspectie. Wat is mijn aandeel in de oplossing van het gevecht van mijn kind? De therapie wil de ouders - en bij uitbreiding het hele gezin - helpen om met een brede blik te kijken naar de eetstoornis van hun kind (Boszormenyi-Nagy \& Krasner, 1986).

De doelstelling van de ouderbegeleiding in Empathie is vierledig: cohesie (de therapie moet ervoor zorgen dat ouders samen opkomen als een team), consistentie (ouders leren om dezelfde aanpak te blijven hanteren over een langere periode), communicatie (ouders leren om negatieve gevoelens te communiceren en voor zichzelf op te komen) en conflicthantering (ouders leren om op een constructieve manier om te gaan met conflicten) (Lask \& BryantWaugh, 1997).

\subsubsection{Dagcentrum}

Voor sommige patiënten is de combinatie van consultaties en ouderbegeleiding voldoende, maar andere patiënten hebben nood aan een intensievere begeleiding. Deze patiënten volgen, aanvullend op de individuele consultaties, een groepsprogramma in het dagcentrum van Empathie. Dat groepsprogramma biedt plaats aan zes patiënten en wordt opgebouwd rond vijf verschillende modules: denkfouten, emoties, zelfwaarde en zelfbeeld, body-image en food. Hierbij is te denken aan psycho-educatie i.v.m. de gevolgen van AN voor de plasticiteit van de hersenen, oefeningen om automatisch negatieve gedachten (zogenaamde ANGels) om te buigen tot positieve gedachten, het gebruik van elementen uit Cognitive Remediation Therapy (CRT), het aanleren van een vocabularium om over emoties te kunnen praten en schrijven, creatieve opdrachten waarin patiënten op zoek gaan naar de eigen sterktes, het gebruik van beelden uit magazines en reclame om een verstoord lichaamsbeeld om te buigen tot een positieve houding tegenover het eigen lichaam, etc. (Friedrich \& Herzog, 2011; Grabe e.a., 2008; Harrison e.a., 2009; Pretorius \& Tchanturia, 2007; Schmidt \& Treasure, 2006;

Tchanturia \& Hambrook, 2010).

Deze modules worden door de patiënten doorlopen gedurende een periode van ongeveer drie maanden. Het dagcentrum is twee dagen per week open. De dagindeling in het dagcentrum wordt telkens opgebouwd volgens dezelfde vaste structuur, waarbij om 10 uur wordt gestart en om 16 uur wordt afgesloten met afspraken voor huiswerk.

Het ochtendprogramma bestaat uit psycho-educatie, waarin de patiënten informatie krijgen over de invloed van AN op de cognitieve flexibiliteit van de hersenen, wat er gebeurt in je 
lichaam, de link tussen AN en achterliggende problematieken, etc. Deze informatie zet patiënten aan tot zelfreflectie en zorgt voor een groter zelfbewustzijn, waardoor hun zelfbeeld kan verschuiven van slachtoffer naar actieve actor die het eigen leven in handen heeft (Pettersen e.a., 2011; Surgenor e.a., 2000).

$\mathrm{Na}$ de psycho-educatie volgt een sessie mindfulness. Korte groepsoefeningen worden aangevuld met individuele trainingen, aangepast aan de kenmerken van de patiënt en diens behandelnoden op dat punt in de therapie. Een dergelijke trainingssessie duurt ongeveer een uur en heeft verschillende doelstellingen. In deze sessies leren patiënten opnieuw tot rust komen en gewaarworden, zowel emotioneel (hoe voel ik me?) als fysiek (wat geeft mijn lichaam aan?). Een ander belangrijk aspect van de training is het leren opmerken van de eigen gedachten en stilstaan bij pijnlijke innerlijke belevingen, in plaats van ze te vermijden. Centraal staat geen proces van verandering, maar een proces van aanvaarding dat ruimte creëert voor verandering, groei en herstel (Spaans e.a., 2005). Deze doelstellingen vertalen zich in meditatieve oefeningen, ontspanningsoefeningen, bewegingsoefeningen, de body scan (een oefening waarbij je stapsgewijs al je lichaamsdelen 'scant' om je zo bewust te worden van wat er in je omgaat), het analyseren van de eigen gedachten, etc. De mindfulness-training wordt nooit opgestart aan het begin van de therapie, omdat bepaalde oefeningen, zoals de body scan, aanvankelijk vrij confronterend kunnen zijn. Klassieke mindfulness duurt acht weken, maar in Empathie kan deze periode langer of korter zijn. Vaak is er veel herhaling nodig in de sessies, waardoor het proces trager verloopt. Bij jongere patiënten worden de ouders ook uitgenodigd om een sessie mee te volgen, zodat ze thuis kunnen opvolgen of de patiënt echt juist geïnterpreteerd heeft wat de mindfulness-coach overbracht.

Na de lunch wordt op een creatieve en luchtige manier gewerkt rond een bepaalde module, bijvoorbeeld door het maken van een collage, het visueel in kaart brengen van je familie, het maken van juwelen, etc. Op regelmatige basis maakt ook dramatherapie deel uit van het namiddagprogramma. Daar ligt de focus op ervaringsleren, als essentiële aanvulling op de verbale therapie binnen Empathie. Binnen een veilige omgeving en aan de hand van theatertechnieken krijgen de patiënten de kans om emoties uit te testen, een nieuwe rol te proberen, plezier te maken, etc.

Aan het einde van de dag krijgen de patiënten een huiswerkopdracht of een denkoefening mee naar huis, die aansluit bij de een van de modules. Een voorbeeld hiervan is: 'schrijf de negatieve gedachten die je in de komende week hebt neer, en hoe je die zou kunnen ombuigen 
tot positieve gedachten'. Deze huiswerkopdrachten worden door de patiënten neergepend in een schriftje en wekelijks besproken in het dagcentrum. Het geven van huiswerk zorgt ervoor dat patiënten, ook op momenten dat ze niet in het dagcentrum zijn, een zekere houvast hebben. Ook leren ze de tips die ze in de therapie meekrijgen toe te passen in de praktijk op een veilige manier. Ook het schriftje is van belangrijke waarde, want het geeft een overzicht van de evolutie die de patiënten reeds doormaakten.

\subsection{Duur en fasering van de behandeling}

De consultaties en de ouderbegeleiding zijn nauw met elkaar verbonden en vormen het fundament van het Empathie-programma. De intensiteit en hoeveelheid van deze sessies is afhankelijk van de zorgbehoefte van de patiënt en de mate waarin de patiënt in staat is om naar school te gaan of een beroep uit te oefenen. Zoals hierboven reeds vermeld, wordt het modulair groepsprogramma slechts door een deel van de patiënten gevolgd, afhankelijk van hun zorgbehoefte. Het modulair programma strekt zich uit over een periode van drie maanden.

In totaal blijven patiënten gemiddeld voor een periode van minstens een jaar in behandeling bij Empathie. Omdat AN gekenmerkt wordt door een traag herstelproces en een sombere prognose zijn niet alle patiënten na deze periode volledig hersteld van AN. Ook hebben sommige patiënten nood aan een meer intensieve begeleiding in een residentieel centrum of een ziekenhuisopname. In die gevallen gaan de therapeuten van Empathie actief op zoek naar een volgende passende behandelingsvorm. Na de begeleidingsperiode voorziet Empathie een lange follow-up periode, waarin op regelmatige basis consultaties blijven plaatsvinden. Ook blijven de therapeuten beschikbaar voor de patiënten via telefoon en e-mail.

\subsection{Behandeldoelen}

De belangrijkste doelstelling die Empathie nastreeft is ervoor zorgen dat de patiënt zichzelf opnieuw toelaat om te functioneren zonder angst. Dat betekent enerzijds dat eten niet meer gepaard gaat met angst. Anderzijds houdt dat ook in dat de dagindeling en keuzes van de patiënt niet langer bepaald worden door eten. Hieraan gerelateerd stelt Empathie nog andere behandeldoelen voorop, zowel op intra- als interpersoonlijk vlak:

\subsubsection{Authenticiteit}


Wanneer een patiënt erin slaagt om de negatieve gedachten en attitudes tegenover zichzelf los te koppelen van zijn/haar 'authentieke' persoonlijkheid, ontstaat er een soort niche waarin dit authentieke zelf verder kan groeien. AN-patiënten worstelen vaak met een innerlijk conflict over de ware aard van hun 'zelf'. In hoeverre zijn hun keuzes, emoties en verlangens authentiek? Binnen een dergelijke niche wordt het echter mogelijk voor de patiënt om de eigen authentieke persoonlijkheid te begrijpen, te accepteren en verder te ontwikkelen (Hope e.a., 2011). Authenticiteit betekent dat je je bewust bent van de keuzes die je maakt, jezelf durft te zijn en het beste uit jezelf durft te halen. Ook zich opnieuw verbonden voelen met anderen is een belangrijke pijler in de behandeling, omdat AN-patiënten zich vaak eenzaam en onbegrepen voelen. Wanneer de patiënt voelt dat de context begrijpt waar hij/zij zo mee worstelt, werkt dat angstreducerend. Een belangrijke doelstelling is daarom het aanleren van een taal aan de ouders om die boodschap over te brengen. Daarnaast is het cruciaal dat ook de patiënt zelf leert om zich te verbinden met anderen en anderen opnieuw leert vertrouwen.

\subsubsection{Zich kwetsbaar durven opstellen.}

AN-patiënten hebben vaak angst om zich bloot te stellen aan emoties, omdat ze kwetsbaarheid zien als een 'zwakte'. Je kwetsbaar opstellen is echter een sterkte. Wie zich kwetsbaar opstelt, durft immers het risico nemen om zich bloot te stellen aan zowel positieve als negatieve invloeden. Wanneer AN-patiënten deze omslag durven maken, kunnen ze zichzelf opnieuw leren waarderen.

\subsubsection{Zelfcompassie}

Een belangrijke doelstelling is het hebben van voldoende geloof in het feit dat je de kracht hebt om een oplossing te vinden voor de tegenslagen en ontgoochelingen waar je in het leven mee geconfronteerd wordt. Het opbouwen van veerkracht is hierbij van centraal belang. Zelfcompassie betekent mild leren zijn voor zichzelf en voor zichzelf leren zorgen. Het vormt een sterke buffer tegen de impact van negatieve gebeurtenissen (Leary e.a., 2007).

Op medisch vlak tracht Empathie haar patiënten aan te moedigen om in therapie te blijven tot een veilig gewicht bereikt is. In sommige gevallen is de patiënt hier nog niet toe in staat, en wordt doorverwezen naar een andere passende zorgvorm. In die gevallen fungeert Empathie als een 'tussenstation' in de behandeling.

\subsection{Sterktes en valkuilen}


Een van de centrale krachtpijlers van de Empathie-aanpak is dat de ouders actief betrokken worden gedurende het volledige behandelproces van hun kind. Dat houdt in dat ouders bereid geacht worden om de 'taal van de eetstoornis' te leren begrijpen. Deze nauwe betrokkenheid vormt echter ook een valkuil, en dit om verschillende redenen. Ouders hebben aan het begin van het behandelverloop meestal weinig inzicht in de ziekte van hun kind. Wanneer ze dan niet bereid zijn om actief deel uit te maken van de behandeling, verloopt het therapeutische proces van hun kind dikwijls zeer moeizaam. Ouders zijn m.a.w. een onmisbare schakel binnen het behandelmodel van Empathie. Een ander aandachtspunt is de fysieke conditie waarin de patiënt zich bevindt bij aanmelding. Aangezien de behandeling in Empathie volledig ambulant is, wordt bij bepaalde patiënten besloten dat het medisch gezien veiliger is om de patiënt eerst te laten aansterken in een residentiële setting. Anderzijds komt het ook voor dat een residentiële behandeling tot betere resultaten leidt wanneer de patiënt reeds een aantal therapiesessies gevolgd heeft bij Empathie. Tenslotte heeft Empathie ook te kampen met een aantal praktische en financiële belemmeringen.

\section{Discussie}

In de geestelijke gezondheidszorg gaan steeds meer stemmen op voor het hanteren van evidence-based behandelvormen, waarvoor er effectbewijs bestaat. Ook patiënten zelf stellen zich steeds meer op als kritische consumenten met hoge kwaliteitseisen aan de geboden hulpverlening (Braet, 2011). Het is echter niet vanzelfsprekend om deze hoge standaard te bereiken in een psychotherapeutische context omwille van de relationele en interpersoonlijke natuur van het therapeutische proces (Sexton \& van Dam, 2010). In onderzoek wordt vaak gefocust op symptomen en stoornissen als primaire kenmerken van patiënten. Deze worden dan gebruikt als evaluatiecriteria van de geteste behandeling. De focus van therapie ligt echter niet louter op het bereiken van bepaalde doelstellingen en symptoomreductie, maar des te meer op het proces dat patiënten doorlopen. Bovendien is statistische significantie vaak een beperkte weergave van het dagelijkse leven van patiënten (Kazdin, 2008). Evidence-based practice (EBP) wordt meestal bekeken in termen van rationaliteit, waardoor niet elke vorm van evidentie even krachtig is (Hamilton, 2005; Rycroft-Malone e.a., 2004). Observaties, descriptief onderzoek, opinies, etc. dragen minder geloofwaardigheid in zich dan Randomized Controlled Trials (RCT's) die als gouden standaard beschouwd worden (Broekaert e.a., 2010). Deze bedenkingen zouden een verklaring kunnen zijn voor het gebrek aan een sterke 
empirische basis voor de behandeling van AN. Daar komt nog bij dat de ziekte gekenmerkt wordt door een sombere prognose en een onvoorspelbaar herstelproces. Evidence-based richtlijnen over de behandeling van $\mathrm{AN}$ worden gelimiteerd door de kwaliteit van het beschikbare wetenschappelijke onderzoek en de klinische relevantie daarvan (Wilson \& Shafran, 2005).

Het beschrijven van een therapeutische interventie, zoals Empathie, op basis van wetenschappelijk gefundeerde parameters wordt door sommigen echter gezien als een eerste fundamentele stap in de richting van EBP (Bond e.a., 2010; Braet, 2011; Veerman \& Van Yperen, 2007). Hiervoor zijn verschillende redenen. Ten eerste worden de klinische expertise en praktijkervaring van professionals mee in acht genomen bij de beschrijving. Daardoor wordt tacit knowledge ('verborgen kennis') zichtbaar en kan er een uitwisseling van kennis en expertise ontstaan tussen verschillende praktijken (Veerman \& Van Yperen, 2007). Daarnaast vormt het beschrijven van de eigen werking in haar ideaaltypische vorm een goed aanknopingspunt voor het evalueren van de werking in de praktijk, omdat werkpunten worden blootgelegd. Zo wordt bijvoorbeeld duidelijk dat in Empathie geen systematische treatment integrity checks worden toegepast om de eigen werking te evalueren. Tot slot vormt een beschrijving een goede basis voor verdere effectstudies (Bond e.a., 2010). Wanneer een interventie grondig beschreven wordt, komt ze met andere woorden vanzelf in een kwaliteitscyclus terecht (Veerman \& Van Yperen, 2007).

Verder onderzoek is noodzakelijk om uitspraken te kunnen doen over de kwaliteit van de zorg en de effectiviteit van de therapie die in Empathie wordt aangeboden. Meestal wordt hierbij enkel gefocust op objectieve en meetbare uitkomsten van een behandeling. Toch gaan er ook stemmen op binnen de medische en therapeutische sector voor Values-Based Practice (VBP) als waardevolle aanvulling op dit rationele evidence-based perspectief (Fulford, 2011; Petrova e.a., 2006). VBP weerspiegelt de diversiteit aan waarden, zowel van de therapeut als de patiënt. In dat opzicht vormt VBP een belangrijke partner van EBP, omdat zo de best beschikbare evidentie verbonden wordt met de waarden die op elkaar inspelen binnen een therapeutische setting. Fulford (2011) benadrukt het belang van het transparant maken van deze waarden, omdat ze de centrale drijfkracht vormen van een interventie.

Een van de centrale waarden binnen Empathie is kwaliteit van bestaan. Tijdens de therapie tracht men ervoor te zorgen dat patiënten zichzelf zo snel mogelijk opnieuw toelaten om te functioneren zonder angst. Hierbij wordt gerespecteerd dat elke patiënt een persoonlijke 
invulling geeft aan kwaliteit van bestaan en het concept 'herstel'. Gerelateerd hieraan wordt ook empowerment belangrijk geacht binnen Empathie. Vanuit de focus op hun eigen sterktes worden patiënten aangemoedigd om weer krachtig op eigen benen te staan. Ook empathie en warmte zijn onmisbare waarden. Het therapiecentrum wil een plaats zijn waar patiënten tot rust kunnen komen en zich op hun gemak kunnen voelen. Daarom wordt veel aandacht besteed aan het inrichten van een warme en aangename setting, waarbinnen een therapeutische relatie kan opgebouwd worden. Een andere waarde die wordt nagestreefd in Empathie is beschikbaarheid. De therapeuten trachten de drempel naar Empathie zo laag mogelijk te maken. Dat betekent enerzijds dat in er een lange follow-up periode wordt voorzien na het afronden van de behandeling. Anderzijds kunnen patiënten zo goed als 24/24 en $7 / 7$ telefonisch terecht bij de therapeuten via telefoon of e-mail.

Bovenstaande waarden geven Empathie mee vorm en zetten de contouren voor de behandeling. Het is pas in de interactie tussen deze waarden, de individuele waarden van de therapeuten en de patiënt en de best beschikbare wetenschappelijke evidentie dat een behandeling tot bepaalde uitkomsten leidt. Net omwille van de beperkte empirische basis voor de behandeling AN kan het waardevol zijn om niet enkel objectief meetbare criteria, maar ook de waarden waarop een behandeling gebouwd is in acht te nemen bij de evaluatie ervan. Door het beschrijven en transparant maken van de werking wordt voor het therapeutisch centrum Empathie een eerste stap gezet.

\section{Acknowledgements}

Dit artikel kwam tot stand binnen een onderzoeksproject naar de perceptie van kwaliteit van bestaan door anorexia-patiënten en hun familie, met dank aan Empathie voor de financiële ondersteuning hiervan.

\section{Summary}

Anorexia Nervosa: an integrative treatment model

Anorexia Nervosa is an illness with a pessimistic prognosis and a big impact on the lives of individuals and their context. Despite the great variety of treatment models the treatment of AN remains characterized by poor empirical support and a high drop-out. In recent years, however, there has been an increase in multidisciplinary treatment models in which different 
methods are combined. Due to the limited scientific evidence it is necessary to describe these integrative models extensively. In doing so, different practices can interact with each other and exchange their knowledge and expertise. In this article the daily practice of Empathie, a therapeutic center for the treatment of AN in Ghent (Belgium) is described. In the therapeutic model of Empathie a systems perspective is combined with aspects of solution-focused therapy.

\section{Literatuur}

Alberts, H.J.E.M., Thewissen, R., \& Raes, L. (2012). Dealing with problematic eating behavior. The effects of a mindfulness-based intervention on eating behavior, food cravings, dichotomous thinking and body image concern. Appetite, 58(1), 847-851.

American Psychiatric Association. (2013). Diagnostic and statistical manual of mental disorders $\left(5^{\text {th }}\right.$ ed.). Arlignton, VA: American Psychiatric Publishing

Bateson, G. (1980). Mind and Nature: A Necessary Unity. New York: Bantam Books.

Berg, K.C., \& Wonderlich, S.A. (2013). Emerging Psychological Treatment in the Field of Eating Disorders. Current Psychiatry Reports, 15(407), 1-9.

Bond, G.R., Drake, R.E., \& Becker, D.R. (2010). Beyond Evidence-Based Practice: Nine Ideal Features of a Mental Health Intervention. Research on Social Work Practice, 20(5), 493-501.

Boszormenyi-Nagy, I., \& Krasner, B.R. (1986). Between give and take: a clinical guide to contextual therapy. New York: Brunner/Mazel.

Braet, C. (2011). Protocollair behandelen in de kinderpsychotherapie. Tijdschrift Klinische Psychologie, 41(3), 148-158.

Broekaert, E., Autrique, M., Vanderplasschen, W., \& Colpaert, K. (2010). 'The Human Prerogative': A Critical Analysis of Evidence-Based and Other Paradigms of Care in Substance Abuse Treatment. Psychiatric Quarterly, 81, 227-238.

Connan, F., Campbell, I.C., Katzman, M., Lightman, S.L., \& Treasure, J. (2003). A neurodevelopmental model for anorexia nervosa. Psychology \& Behavior, 79, 13-24. 
Dillen, A. (2004). Ongehoord vertrouwen: Ethische perspectieven vanuit het contextuele denken van Ivan Boszormenyi-Nagy. Antwerpen: Garant.

Fairburn, C. (2005). Evidence-based treatment of anorexia nervosa. International Journal of Eating Disorders, 37, S26-S30.

Figley, C.R., \& Kiser, L.J. (2013). Helping Traumatized Families. New York: Routlegde.

Friedrich, H.C., \& Herzog, W. (2011). Cognitive-Behavioral Flexibility in Anorexia Nervosa. In R.A.H. Ada \& W.H. Kaye (Eds.), Behavioral Neurobiology of Eating Disorders (pp. 111123). New York: Springer.

Fulford, K.W.M. (2011). The value of evidence and the evidence of values: bringing together values-based and evidence-based practice in policy and service development in mental health. Journal of Evaluation in Clinical Practice, 117, 976-987.

Goodier, G.H.G., McCormack, J., Egan, S.J., Watson, H.J., Hoiles, K.J., Todd, G., \& Treasure, J.L. (2014). Parent Skills Training Treatment for Parents of Children and Adolescents with Eating Disorders: A Qualitative Study. International Journal of Eating Disorders, 47(4), 368-375.

Grabe, S., Ward, L.M., \& Hyde, J.S. (2008). The Role of the Media in Body Image Concerns Among Women: A Meta-Analysis of Experimental and Correlational Studies. Psychological Bulletin, 134(3), 460-476.

Grover, M., Naumann, U., Mohammed-Dar, L., Glennon, D., Ringwood, S., Eisler, I., ... Schmidt, U. (2011). A randomized controlled trial of an Internet based cognitive-behavioral skills package for carers of people with anorexia nervosa. Psychological Medicine, 41(12), 2581-2591.

Guarda, A.S. (2008). Treatment of anorexia nervosa: Insights and obstacles. Psychology \& Behavior, 94, 113-120.

Hamilton, J. (2005). The Answerable Question and A Hierarchy of Evidence. American Academy of Child and Adolescent Psychiatry, 44(6): 596-600.

Harrison, A., Sullivan, S., Tchanturia, K., \& Treasure, J. (2009). Emotion Recognition and Regulation in Anorexia Nervosa. Clinical Psychology and Psychotherapy, 16, 348-356. 
Hatch, A., Madden, S., Kohn, M., Clarke, S., Touyz, S., \& Williams, L.M. (2010). Anorexia Nervosa: Towards An Integrative Neuroscience Model. European Eating Disorders Review, $18,165-179$.

Hope, T., Tan, J., Stewart, A., \& Fitzpatrick, R. (2011). Anorexia Nervosa and the Language of Authenticity. Hastings Center Report, 41(6), 19-29.

Hoyle, D., Slater, J., Williams, C., Schmidt, U., \& Wade, T.D. (2013). Evaluation of a webbased skills intervention for carers of people with anorexia nervosa: A randomized controlled trial. International Journal of Eating Disorders, 46, 634-638.

Jones, A., Evans, M., BAmford, B., \& Ford, H. (2008). Exploring Quality of Life For EatingDisordered Patients. European Eating Disorders Review, 16, 276-286.

Kazdin, A.E. (2008). Evidence-Based Treatment and Practice: New Opportunities to Bridge Clinical Research and Practice, Enhance the Knowledge Base, and Improve Patient Care. American Psychologist, 63(3), 146-159.

Korzybski-Instituut. (2014). Geraadpleegd via http://www.korzybski-international.com.

Lask, B., \& Bryant-Waugh, R. (1997). Prepubertal Eating Disorders. In D.M. Garner \& P.E. Garfinkel (Eds.), Handbook of Treatment for Eating Disorders (pp.476-483). New York: The Guilford Press.

Leary, M.R., Tate, E.B., Adams, C.E., Allen, A.B., \& Hancock, J. (2007). Self-Compassion and Reactions to Unpleasant Self-Relevant Events: The Implications of Treating Oneself Kindly. Journal of Personality and Social Psychology, 92(5), 887-904.

Lock, J., \& Le Grange, D. (2001). Can Family-Based Treatment of Anorexia Nervosa Be Manualized? The Journal of Psychotherapy Practice and Research, 10(4), 253-261.

National Institute for Clinical Excellence (NICE). (2004). Core interventions in the treatment and management of anorexia nervosa, boulimia nervosa and binge eating disorder. London: British Psychology Society.

Petrova, M., Dale, J., \& Fulford, K.W.M. (2006). Values-based practice in primary care: easing the tension between individual values, ethical principles and best evidence. British Journal of General Practice, 56, 703-709. 
Pettersen, G., Rosenvinge, J.H., \& Wynn, R. (2011). Eating disorders and psychoeducation patients' experiences of healing processes. Scandinavian Journal of Caring Sciences, 25, 1218.

Pretorius, N., \& Tchanturia, K. (2007). Anorexia nervosa: how people think and how we address it in cognitive remediation therapy. Therapy, 4(4), 423-431.

Rycroft-Malone, J., Seers, K., Titchen, A., Harvey, G., Kitson, A., \& McCormack, B. (2003). What counts as evidence in evidence-based practice? Journal of Advanced Nursing, 47(1), 8190.

Schmidt, U., \& Treasure, J. (2006). Anorexia nervosa: Valued and visible. A cognitiveinterpersonal maintenance model and its implications for research and practice. British Journal of Clinical Psychology, 45, 343-366.

Schmidt, U., Wade, T.D., \& Treasure, J. (2014). The Maudsley Model of Anorexia Nervosa Treatment for Adults (MANTRA): Development, Key Features, and Preliminary Evidence. Journal of Cognitive Psychotherapy: An International Quarterly, 28(1). doi:10.1891/08898391.28.1.1.

Sexton, T.L., \& van Dam, A.E. (2010). Creativity Within the Structure: Clinical Expertise and Evidence-Based Treatments. Journal of Contemporary Psychotherapy, 40, 175-180.

Smit, T., Offringa, C., \& Kramer, H. (2009). Mindful spiegelexposure bij eetstoornissen: een nieuwe therapieprotocol en twee gevalsbeschrijvingen. Directieve therapie, 29(2), 93-111. Spaans, J., van de Kamp-Verbeij, M.L., \& Hop, H. (2005). Mindfulness-oefeningen: een welkome bijdrage aan de behandeling van anorexia nervosa. Directieve therapie, 25, 276-299. Steinhausen, H.C. (2002). The outcome of anorexia nervosa in the $20^{\text {th }}$ century. The American Journal of Psychiatry, 159, 1284-1293.

Steinhausen, H.C. (2008). Outcome of Eating Disorders. Child \& Adolescent Psychiatric Clinics of North America, 18, 225-242.

Stinckens, N. (2001). Werken met de innerlijke criticus. Gerichte empirische verkenning van een cliëntexperiëntiële microtheorie. Doctoraatsverhandeling, K.U. Leuven. 
Surgenor, L.J., Rau, J., Snell, D.L., \& Fear, J.L. (2000). Educational Needs of Eating Disorder Patients and Families. European Eating Disorders Review, 8, 59-66.

Tchanturia, K., \& Hambrook, D. (2010). Cognitive Remediation Therapy for Anorexia Nervosa. In C.M. Grilo \& J.E. Mitchell (red.), The Treatment of Eating Disorders (pp. 130149).New York: The Guilford Press.

Tenwolde, A. (2001). Wat zijn momenteel de belangrijkste behandelmethoden voor eetstoornissen? Psychopraxis, 3, 39-42.

Veerman, J.W., \& van Yperen, T.A. (2007). Degrees of freedom and degrees of certainty: A developmental model for the establishment of evidence-based youth care. Evaluation and Program Planning, 30, 212-221.

Wade, T.D., Treasure, J., \& Schmidt, U. (2011). A case series evaluation of the Maudsley Model for treatment of adults with anorexia nervosa. European Eating Disordes Review, 19, 382-389.

Witty, M.C. (2007). Client-Centered Therapy. In: N. Kazantzis \& L. L'Abate. Handbook of Homework Assignments in Psychotherapy: Research, Practice, and Prevention. New York: Springer. 